\title{
COMPARISON OF DAMPING PERFORMANCE OF CONVENTIONAL AND NEURO-FUZZY BASED POWER SYSTEM STABILIZERS APPLIED IN MULTI-MACHINE POWER SYSTEMS
}

\author{
Duraiswamy Murali* — Marimuthu Rajaram ${ }^{* *}$
}

\begin{abstract}
The objective of this paper is to investigate the power system damping enhancement via power system stabilizers (PSSs). However, the conventional power system stabilizers (CPSSs) have certain drawbacks. There are many techniques proposed in the literature for damping improvement of low frequency power system oscillations. In this paper, adaptive neuro-fuzzy inference system (ANFIS) technology has been proposed to coordinate the CPSSs in a multi-machine power system. The time-domain simulations are carried out in Matlab/Simulink environment to validate the effectiveness of the proposed control scheme under different operating conditions.
\end{abstract}

K e ywords: ANFIS, CPSS, damping enhancement, low frequency oscillations, multi-machine power system, timedomain simulation

\section{INTRODUCTION}

Since the development of large interconnected power systems, there have been spontaneous system oscillations at very low frequencies in the order of $0.2-3 \mathrm{~Hz}$. Once started, the oscillation would continue for a while and then disappear, or continue to grow, causing system separation [1]. Two electromechanical modes of oscillations are reported [2]: (i) local mode, with a frequency 0.8-3 $\mathrm{Hz}$, which is related to oscillation in a single generator or a group of generators in the same area oscillate against each other, and (ii) inter-area mode, with frequency $0.2-$ $0.8 \mathrm{~Hz}$, in which the generator units in one area oscillate against those in other area.

In order to damp these power system oscillations and increase system oscillations stability, the installation of Power System Stabilizer (PSS) is both economical and effective. PSSs have been used for many years to add damping to electromechanical oscillations. To date, most major electric power system plants in many countries are equipped with PSS [3].

Klein et al $[4,5]$ presented the simulation studies into the effects of stabilizers on inter-area and local modes of oscillations in interconnected power systems. It was shown that the PSS location and the voltage characteristics of the system loads are significant factor in the ability of a PSS to increase the damping of inter-area oscillations.

Nowadays, the conventional lead-lag power system stabilizer (CPSS) is widely used by the power system utility [6]. Other types of PSS such as proportional-integral power system stabilizer (PI-PSS) and proportional-integral derivative power system stabilizer (PID-PSS) have also been proposed [7, 8]. However, CPSSs are not able to provide satisfactory results over wider ranges of operating conditions [9].
To overcome this problem, Fuzzy logic based technique is used for designing of PSSs. Fuzzy logic controllers (FLCs) are very useful in the case a good mathematical model for the plant is not available, however, experienced human operators are available for providing qualitative rules to control the system [9]. Also Hybrid PSSs using fuzzy logic and/or neural networks or Genetic Algorithms have been reported in some literature to improve the performance of Fuzzy logic based PSSs [10,11].

This paper describes the design of neuro-fuzzy adaptive stabilizers, which have a fuzzy logic design base and use neural network to adjust the fuzzy logic parameters. The ANFIS based PSS uses a first-order Sugeno-type fuzzy logic controller whose membership functions (MFs) and consequences are tuned by back-propagation method.

The proposed technique is illustrated on a 9-bus, 3machine power system. MATLAB/SIMULINK and fuzzy logic toolbox have been used for system simulation. The results demonstrate that the proposed ANFIS based PSS improved the damping of power system oscillations over a conventional PSS.

\section{MODEL OF POWER SYSTEM UNDER STUDY}

Inter-area oscillation control problem is examined by considering a 3-machine 9-bus power system model, whose single line diagram representation is shown in Fig. 1 where all impedance values are marked in per unit on 100 MVA base [12]. The system frequency is $50 \mathrm{~Hz}$. In Fig. 1, the bus 1, to which generator G1 is connected, is considered as reference bus. The details of generators data $[13,14]$ are given in Appendix. There are two sets of conventional lead-lag PSS used in the system; one PSS connected in Area 1 (G2) and another one in Area 2 (G3).

Electrical and Electronics Engineering, Government College of Engineering, Salem 636 011, Tamilnadu, India, muralid36@yahoo.com, ** Electrical and Electronics Engineering, Government College of Technology, Coimbatore 641 013, Tamilnadu, India 


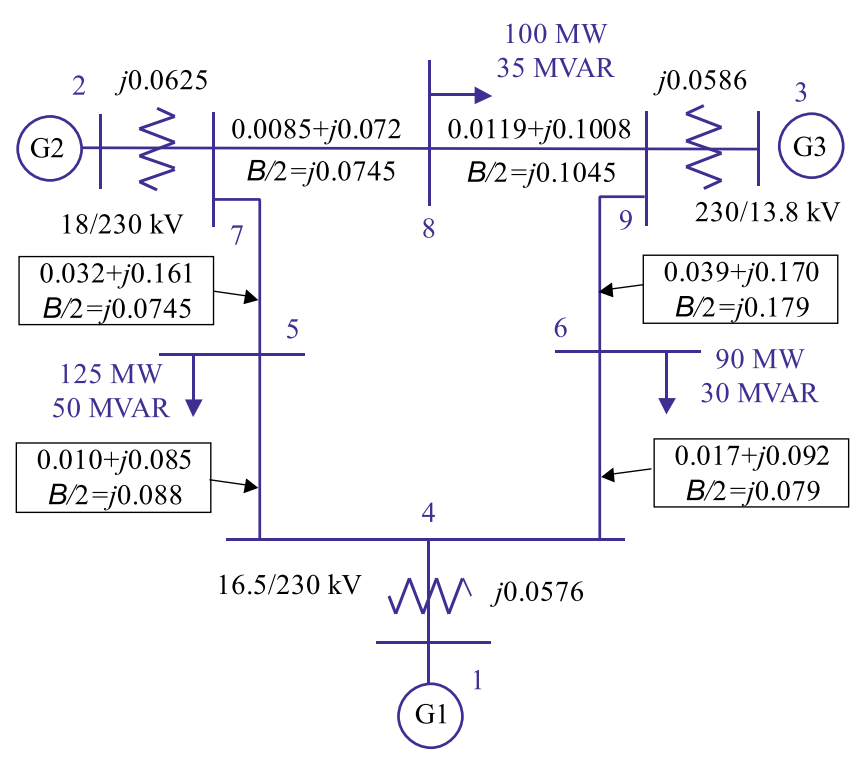

Fig. 1. Single line diagram of a 3-machine 9-bus power system

The reduced $Y_{B U S}$ matrix for the above system is

$Y_{B U S}=$

$$
\left[\begin{array}{ccc}
0.846-j 2.988 & 0.287+j 1.513 & 0.210+j 1.226 \\
0.287+j 1.513 & 0.420-j 2.724 & 0.213+j 1.088 \\
0.210+j 1.226 & 0.213+j 1.088 & 0.277-j 2.368
\end{array}\right] .
$$

\section{CONVENTIONAL POWER SYSTEM STABILIZER (CPSS)}

Without PSS, the system has more oscillations, in power angle and speed deviation, with increased amplitudes and settling times. Hence, PSSs are introduced in the system to provide damping to electromechanical oscillations by increasing the generators damping coefficient. The structure of a conventional lead-lag PSS (CPSS) shown in Fig. 2 has three components; gain block, washout block, and the phase compensation block. The stabilizer gain $K$ determines the amount of damping introduced by PSS. Here, in our work, $K=400$. The signal washout block serving as high pass filter has such a high value of time constant $T_{w}$ that the signals associated with oscillations in $\omega$ are passed without any change. The value of $T_{w}$ used here is $3 \mathrm{~s}$. The phase compensation block is used to provide compensation for the phase lag between exciter input and generator electrical torque. Here, $T_{1}=0.1537 \mathrm{~s}$ and $T_{2}=0.1 \mathrm{~s}$. For the conventional lead-lag PSS, the following transfer function is used

$$
\frac{\Delta U_{P S S}}{\Delta \omega}=\frac{K s T_{w}\left(1+s T_{1}\right)}{\left(1+s T_{w}\right)\left(1+s T_{2}\right)} .
$$

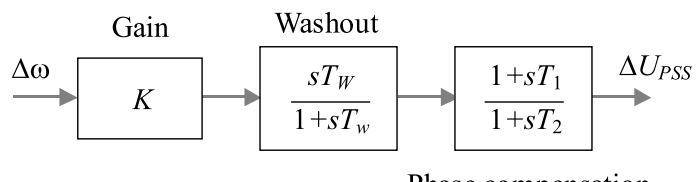

Phase compensation

Fig. 2. Structure of Conventional lead-lag PSS (CPSS)

\section{NEURO-FUZZY BASED POWER SYSTEM STABILIZER}

In this paper, adaptive neuro-fuzzy inference system (ANFIS) technology has been used to coordinate the CPSSs in 3-machine 9-bus power system model shown in Fig. 1. The proposed ANFIS controller uses seven linguistic variables such as: Positive Big (PB), Positive Medium (PM), Positive Small (PS), Zero (ZE), Negative Small (NS), Negative Medium (NM) and Negative Big (NB). The Gaussian membership functions are chosen. The defuzzification process is tested by using the weighted average method.

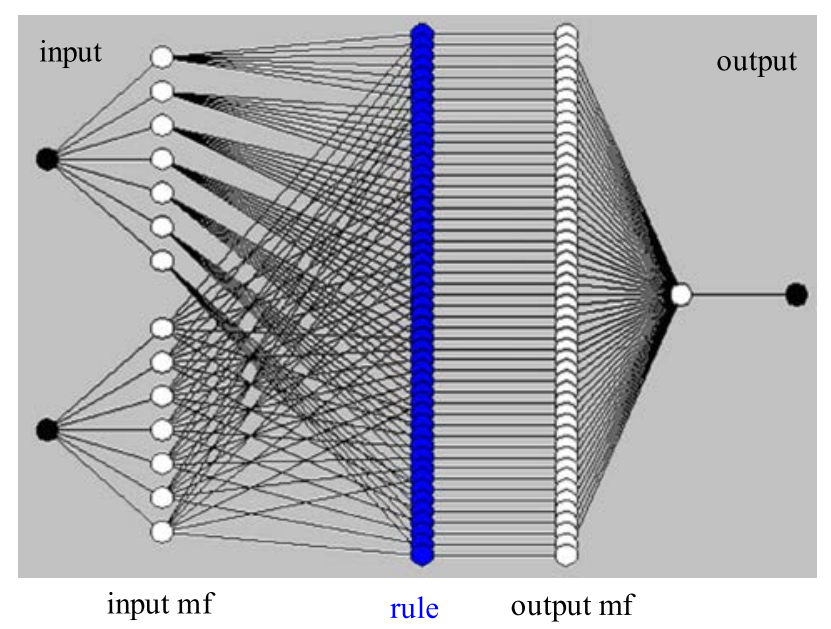

Fig. 3. Structure of proposed ANFPSS for the power system under study

In MATLAB, the ANFIS editor graphics user interface is available in Fuzzy Logic Toolbox [15]. In the ANFIS Editor, the fuzzy inference is generated using grid partitioning method. For grid partitioning, it uses the Fuzzy C-means clustering (FCM) data clustering technique. FCM is a data clustering algorithm in which each 


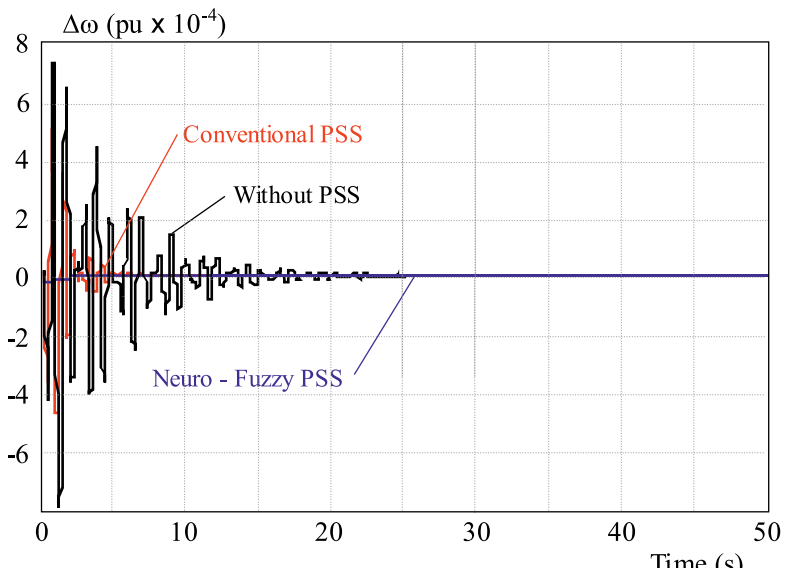

Fig. 4. Dynamic response - angular speed deviation $\Delta \omega \omega$, Area 1 , for $P=0.8 \mathrm{pu}, Q=0.9 \mathrm{pu}$, step torque disturbance $=0.005 \mathrm{pu}$

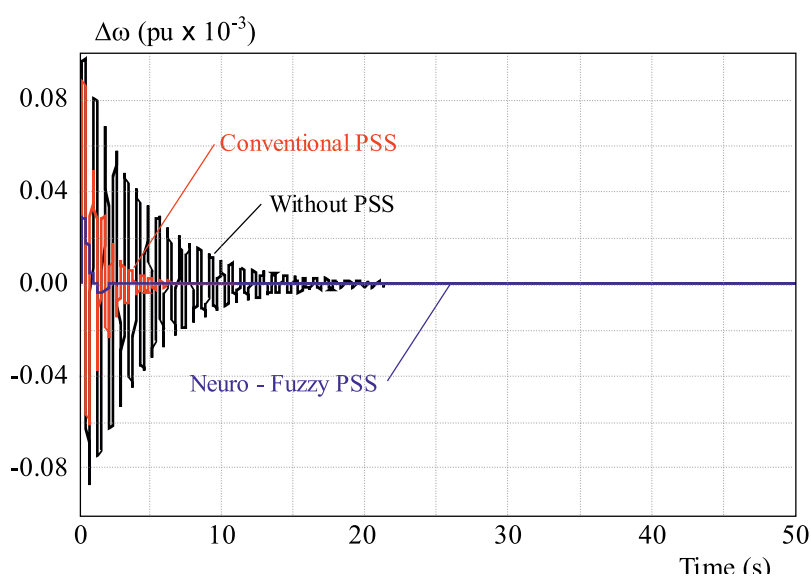

Fig. 6. Dynamic response - angular speed deviation $\Delta \omega$, Area 2 , for $P=0.8 \mathrm{pu}, Q=0.9 \mathrm{pu}$, step torque disturbance $=0.005 \mathrm{pu}$

Table 1. Fuzzy Inference System obtained from the CPSS

\begin{tabular}{|c|c|}
\hline $\begin{array}{l}\text { Deviation } \\
\text { of angular } \\
\text { speed } \\
\Delta \omega\end{array}$ & $\begin{array}{c}\text { Deviation } \\
\text { of angular } \\
\text { acceleration } \\
\Delta \dot{\omega}\end{array}$ \\
\hline & NB NM NS ZE PS PM PB \\
\hline NB & NB NB NB NB NM NS ZE \\
\hline NM & NB NB NM NM NS ZE PS \\
\hline NS & NB NM NS NS ZE PS PM \\
\hline $\mathrm{ZE}$ & NM NM NS ZE ZE PM PM \\
\hline PS & NM NS ZE ZE PS PM PB \\
\hline PM & NS ZE PS PM PM PM PB \\
\hline $\mathrm{PB}$ & $\mathrm{ZE}$ ZE PM PS PB PB PB \\
\hline
\end{tabular}

data point belongs to a cluster with a degree specified by a membership grade. After generating the fuzzy inference system as shown in Table 1, the generated information describing the model structure and parameters of both the

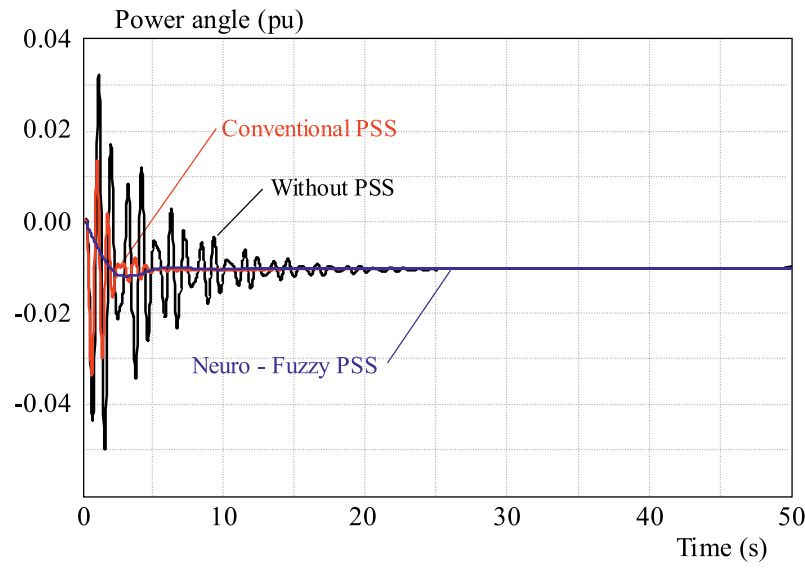

Fig. 5. Dynamic response - power angle, Area 1 , for $P=0.8 \mathrm{pu}$, $Q=0.9 \mathrm{pu}$, step torque disturbance $=0.005 \mathrm{pu}$

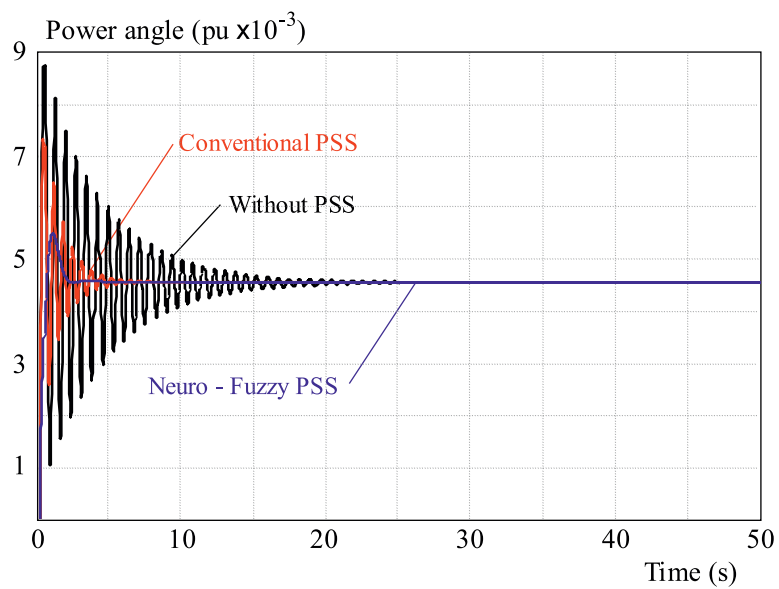

Fig. 7. Dynamic response - power angle, Area 2, for $P=0.8 \mathrm{pu}$, $Q=0.9 \mathrm{pu}$, step torque disturbance $=0.005 \mathrm{pu}$

input and output variables are used in the ANFIS training phase. This information will be fine-tuned by applying the hybrid learning or the backpropagation scheme. The generated model is of a first-order Sugeno's form and the generated rules are as follows

$$
U_{P S S}=p_{i} \Delta \omega+q_{i} \Delta \dot{\omega}+r_{i}
$$

where, $i=\{1, n \times m\}$ refers to the rule numbers, $j=$ $\{1, n\}$ refers to the angular speed deviation error terms in the fuzzy set, $n, m$ refers to the number of terms generated, $k=\{1, m\}$ refers to the acceleration terms in the fuzzy set, $\left\{p_{i}, q_{i}, r_{i}\right\}$ are the $i$-th consequent (PSS output) parameters. The input signals to the ANFIS controller for the PSS are $\Delta \omega$ (deviation of the angular speed) and $\Delta \dot{\omega}$ (deviation of the angular acceleration).

The scheme of proposed ANFPSS and its application in the power system under study is shown in Fig. 3, where the inputs are $\Delta \omega$ and $\Delta \dot{\omega}$ and the output is $\Delta U_{P S S}$.

\section{SIMULATION RESULTS AND DISCUSSION}

Initially, the 3-machine 9-bus power system shown in Fig. 1 is installed with two conventional power system 


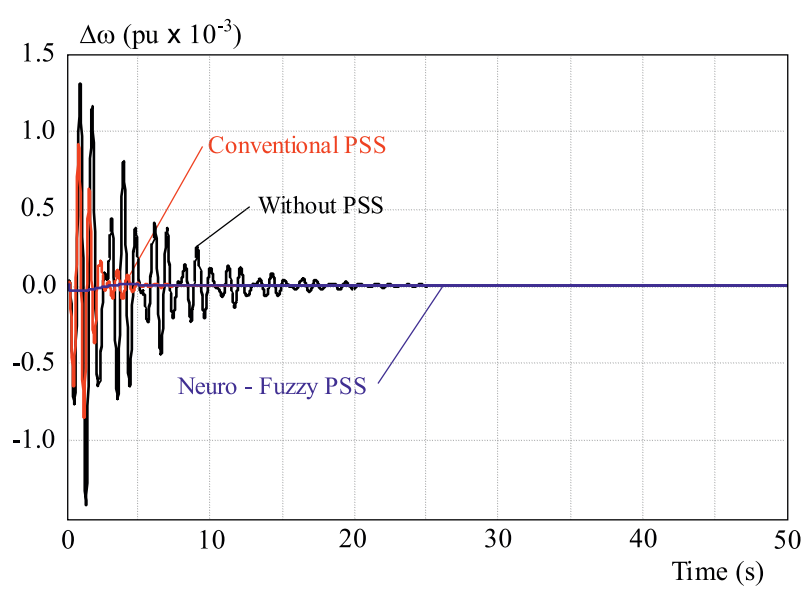

Fig. 8. Effect of increased torque disturbance on angular speed deviation $\Delta \omega$, Area 1 , for $P=0.8 \mathrm{pu}, Q=0.9 \mathrm{pu}$, step torque disturbance $=0.009 \mathrm{pu}$

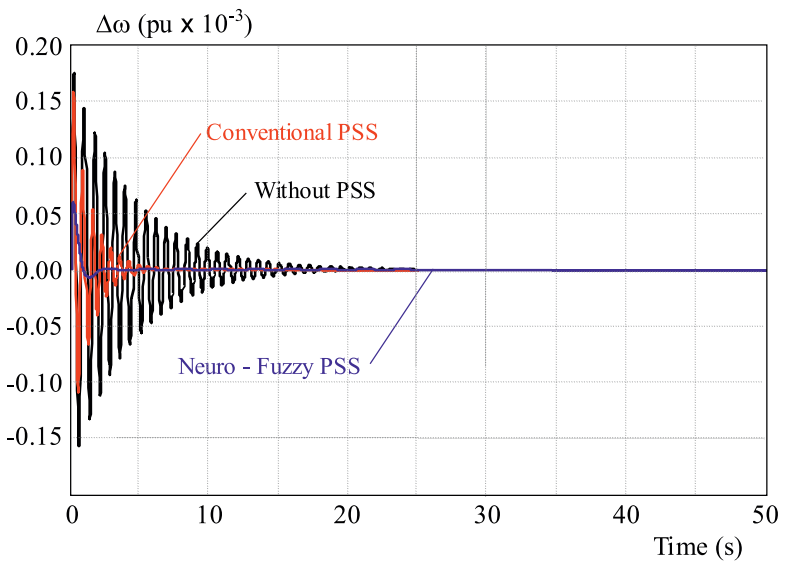

Fig. 10. Effect of increased torque disturbance on angular speed deviation $\Delta \omega$, Area 2 , for $P=0.8 \mathrm{pu}, Q=0.9 \mathrm{pu}$, step torque disturbance $=0.009 \mathrm{pu}$

stabilizers (CPSSs); one in Area 1 (G2) and another one in Area 2 (G3) respectively. The system is simulated in Matlab/Simulink environment with different operating conditions. Here, for illustration, the following two sets of operating conditions are considered in order to test the effectiveness of CPSSs.

(i) Total real power of load $P=0.8 \mathrm{pu}$, total reactive power of load $Q=0.9 \mathrm{pu}$, terminal voltage $V_{t}=$ $1.05 \mathrm{pu}$, step torque disturbance $\Delta T_{m}=0.005 \mathrm{pu}$, and disturbance clearing time is $50 \mathrm{~s}$.

(ii) Total real power of load $P=0.8 \mathrm{pu}$, total reactive power of load $Q=0.9 \mathrm{pu}$, terminal voltage $V_{t}=$ $1.05 \mathrm{pu}$, Step torque disturbance $\Delta T_{m}=0.009 \mathrm{pu}$, and disturbance clearing time is $50 \mathrm{~s}$.

From the simulation results shown in Figs. 4-7, it is inferred that the amplitudes and settling times of speed deviation and power angle oscillations for Area 1 and Area 2 are very high in the absence of PSSs. But after the introduction of CPSSs in the system, the amplitudes and settling times of oscillations are reduced.

To have further improvement in the damping performance of the system, the CPSSs are coordinated using ANFIS control scheme. The system is again simulated in

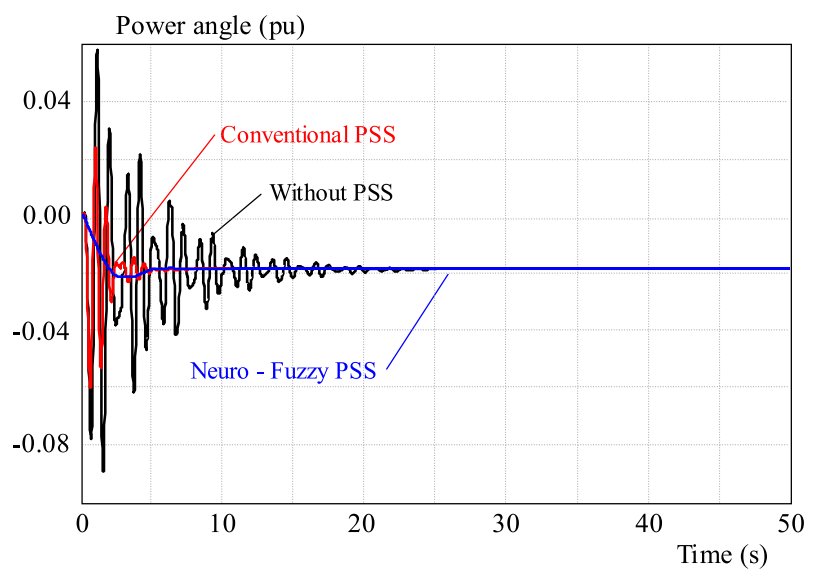

Fig. 9. Effect of increased torque disturbance on power angle, Area 1 , for $P=0.8 \mathrm{pu}, Q=0.9 \mathrm{pu}$, step torque disturbance $=0.009 \mathrm{pu}$

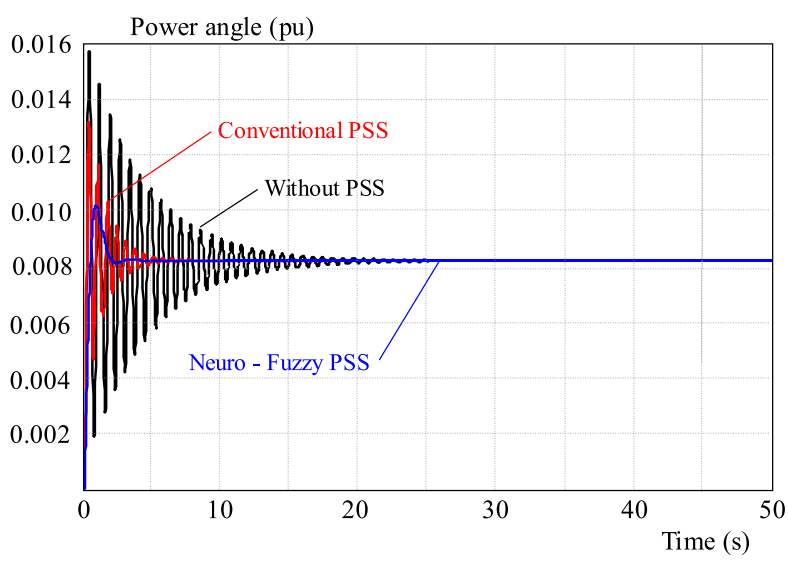

Fig. 11. Effect of increased torque disturbance on power angle, Area 2 , for $P=0.8 \mathrm{pu}, Q=0.9 \mathrm{pu}$, step torque disturbance $=0.009$ $\mathrm{pu}$

Matlab/Simulink environment with same set of operating points in order to validate the efficiency of the proposed ANFIS control scheme. The simulation results are compared with that of CPSSs. The results shown in Figs. 4-7 reveal that the proposed simple and robust ANFIS control scheme has improved the damping performance of the system in terms of very much reduced amplitudes and settling times of oscillations.

When the torque disturbance is increased to 0.009 $\mathrm{pu}$, the system shows somewhat increased amplitude of oscillations in both speed deviation and power angle for Area 1 and Area 2 with almost no change in settling times as shown in Figs. 8-11.

\section{CONCLUSIONS}

The conventional power system stabilizers (CPSSs) suffer from the drawback that they are not able to provide good damping performance over wide range of operating conditions. To overcome this drawback, ANFIS technology has been proposed in this paper to coordinate the CPSSs. The proposed method is evaluated on a 3-machine 9-bus power system model. The time domain simulation results demonstrate that the ANFIS coordinated CPSSs 
can provide a very good damping performance over a wide range of operating conditions and improve stability margin as well, compared to CPSSs. The effects of increased torque disturbance are also analyzed. Thus, the ANFIS based PSSs are able to yield better and fast damping characteristics under small and large disturbances even with changes in system operating conditions.

\section{Appendix}

Data for Generators G2 and G3 in 3-machine 9-bus power system:

Generator G2: Rated $192 \mathrm{MVA}$, Rated voltage = $18 \mathrm{kV}, H(s)=6.4, T_{d 0}^{\prime}=6 \mathrm{~s}, T_{q 0}^{\prime}=0.535 \mathrm{~s}, x_{d}=0.858$, $x_{d}^{\prime}=0.1198, x_{q}=0.8645, x_{q}^{\prime}=0.1969$

Generator G3: Rated 128MVA, Rated voltage = $13.8 \mathrm{kV}, H(s)=3.01, T_{d 0}^{\prime}=5.89 \mathrm{~s}, T_{q 0}^{\prime}=0.6 \mathrm{~s}$, $x_{d}=1.3125, x_{d}^{\prime}=0.1813, x_{q}=1.2578, x_{q}^{\prime}=0.25$.

Reactance values are in pu on a 100 MVA base.

\section{REFERENCES}

[1] SAUER, P. W.-PAI, M. A. KUNDUR: Power System Dynamics and Stability, Prentice Hall, 1998.

[2] ROGERS, G.: Power System Oscillations, Kluwer Academic Publishers, 2000.

[3] WATSON, W.-MANCHUR, G. : Experience with Supplementary Damping Signals for Generator Static Excitation Systems, IEEE Trans. PAS, 92 (Jan 1973), 199-203.

[4] KLEIN, M.et al : A Fundamental Study of Inter-area Oscillations in Power Systems, IEEE Trans. on Power Systems 6 No. 3 (Aug.1991), 914-921.

[5] KLEIN, M.et al : Analytical Investigation of Factors Influencing Power System Stabilizers Performance, IEEE Trans. on Energy Conversion 7 No. 3 (Sept.1992), 382-390.

[6] TSE, G. T.-TSO, S. K.: Refinement of Conventional PSS Design in Multimachine System by Modal Analysis, IEEE Trans. PWRS 8 No. 2 (1993), 598-605.

[7] HSU, Y. Y.-HSU, C. Y.: Design of a Proportional-Integral Power System Stabilizer, IEEE Trans. PWRS 1 No. 2 (1986), $46-53$.
[8] HSU, Y. Y.-LIOU, K. L.: Design of Self-Tuning PID Power System Stabilizers for Synchronous Generators, IEEE Trans. on Energy Conversion 2 No. 3 (1987), 343-348.

[9] HOANG, P.et al: Design and Analysis of an Adaptive Fuzzy Power System Stabilizer, IEEE Trans. on Energy Conversion 11 No. 2 (June 1996), 455-461.

[10] HASHEM, M.et al: A Neuro-Fuzzy Power System Stabilizer with Self-organizing Map for Multi-machine Systems, Proceeding of IEEE Power Engineering Society Transmission and Distribution Conference, 2, 1219-1224 (2002).

[11] MENNITI, D. etal : Damping Oscillation Improvement by Fuzzy Power System Stabilizers Tuned by Genetic Algorithm, 14-th PSCC, Sevilla (2002).

[12] KUNDUR, P.: Power System Stability and Control, Mc Graw-Hill Press, 1994.

[13] ANDERSON, P. M.-FOUAD, A. A.: Power System Control and Stability, Iowa State University Press, Ames, IA, 1977.

[14] YU, Y. N.: Electric Power System Dynamics, Academic Press, 1983

[15] Fuzzy Logic Toolbox, Available: www.mathworks.com.

Received 9 October 2012

Duraiswamy Murali received his BE degree in Electrical Engineering, and ME degree in Power Systems and PhD degree in Electrical Engineering in the year 1992, 2000, and 2012 from the University of Madras, Chennai, and Bharathidasan University, Tiruchirappalli, and Anna University, Chennai respectively. He is now working as Assistant Professor in the department of Electrical and Electronics Engineering, Government College of Engineering, Salem. He has published more than ten papers in various International Journals. His research interests include Power systems, Intelligent Control and Power electronics.

Marimuthu Rajaram received his $\mathrm{BE}, \mathrm{ME}$, and $\mathrm{PhD}$ degrees in Electrical and Electronics Engineering from the University of Madras, Chennai, Kamaraj University, Madurai, and Bharathiar University, Coimbatore, in the year 1981, 1988 and 1993 respectively. He is now working as Professor in the department of Electrical and Electronics Engineering, Government College of Technology, Coimbatore. He has published many papers in various International Journals. His research interests include Power systems, Control systems, Power electronic converters and drives. 